\title{
Üniversite Öğrencilerinde Kronotipe Göre Besin Tüketiminin Değerlendirilmesi
}

\author{
Evaluation of Food Consumption According to Chronotype in University Students
}

\author{
Yasemin Çakır ${ }^{1}$, Neşe Toktaş², Efsun Karabudak ${ }^{3}$
}

Geliş tarihi/Received: 07.06.2018 • Kabul tarihi/Accepted: 15.08.2018

\section{ÖZET}

Amaç: $\mathrm{Bu}$ çalışma, üniversite öğrencilerinin kronotiplerinin belirlenmesi ve kronotiplerine göre besin tüketimlerinin karşılaştırılması amacıyla planlanmış ve yürütülmüştür.

Bireyler ve Yöntem: Çalışmaya yaşları 19-31 yıl arasında olan, 198 erkek (\%24.5) ve 609 kadın (\%75.5) olmak üzere toplam 807 üniversite öğrencisi dahil edilmiştir. Bireylere genel özelliklerinin, beslenme ve uyku alışkanlıklarının sorgulandığı bir anket formu ve kronotipin belirlenmesi için "İnsan Sirkadiyen Ritminde Sabahçll ve Akşamcıl Tipleri Belirlemede Kendi Kendini Değerlendirme Formu” uygulanmıştır. Araştırmacılar tarafından bireylerin iki günlük besin tüketim kaydı alınmış, vücut ağırlığı ve boy uzunluğu ölçümleri standartlara uygun şekilde yapılmıştır. Bireylerin enerji ve besin ögelerinin önerilen günlük yeterli alım düzeylerini karşılama durumları Türkiye Beslenme Rehberi’ne (TÜBER, 2015) göre değerlendirilmiştir.

Bulgular: Katılımclların \%23’ü sabahçıl (n=186), \%52.8’i ara (n=426), \%24.2'si ise akşamcll (n=195) kronotipe sahiptir. Sabahçıl tip bireylerin günlük su tüketimlerinin ara ve akşamcll tip bireylerden anlamlı düzeyde daha fazla olduğu saptanmıştır $(\mathrm{p}=0.000)$. Bireyler antropometrik ölçümlerine göre değerlendirildiğinde sabahçıl bireylerin beden kütle indeksi (BKI) değerlerinin akşamcıl tiplere göre ( $\mathrm{p}=0.014)$ daha yüksek olduğu belirlenmiştir. Araştırmaya katılan sabahçıl bireylerde hafta içi sabah öğününü, hafta sonu ise öğle öğününü atlayanların oranı akşamcıl bireylere göre anlamlı düzeyde daha azdır (sırasıyla p=0.002, p=0.011). Akşamcıl bireylerin günlük enerjinin karbonhidrattan gelen yüzdesi sabahçll bireylerden daha fazladır ( $\mathrm{p}=0.043$ ). Sabahçıl bireylerin ise günlük enerjinin yağdan gelen yüzdesi akşamcıl bireylere göre daha fazladır ( $\mathrm{p}=0.020)$. Sabahçll bireylerin günlük folik asit alım düzeyleri akşamcll bireylere göre daha fazladır ( $\mathrm{p}=0.018)$.

Sonuç: Bu çalışmada üniversite öğrencilerinin farklı kronotipe sahip olmalarına rağmen besin tüketimlerinin benzer olduğu belirlenmiştir. Beslenme, uyku düzeni gibi etmenlerle karşıllklı etkileşim içerisinde bulunan kronotip, fizyolojik süreçlerde değişikliklere neden olabilir. Üniversite öğrencilerinin kronotiplerine göre beslenme durumları prospektif fizyolojik çalışmalar ile desteklenmelidir.

Anahtar kelimeler: Kronotip, sirkadiyen ritim, besin tüketimi

\section{ABSTRACT}

Aim: This study was planned and conducted in order to determine the chronotype of university students and to compare food consumption according to chronotype.

Subjects and Method: A total of 807 university students, 198 male (24.5\%) and 609 female (75.5\%), with aged between of 19-

1. İletişim/Correspondence: Gazi Üniversitesi, Sağlık Bilimleri Fakültesi, Beslenme ve Diyetetik Bölümü, Ankara, Türkiye • E-posta: dytyasemincakir@gmail.com (ㄱ) https://orcid.org/0000-0002-8697-9250
2. Akdeniz Üniversitesi Spor Bilimleri Fakültesi Antrenörlük Eğitimi Bölümü, Antalya, Türkiye • ๑ https://orcid.org/0000-0002-3206-6536

3. Gazi Üniversitesi, Sağllk Bilimleri Fakültesi, Beslenme ve Diyetetik Bölümü, Ankara, Türkiye • ๑ https://orcid.org/0000-0002-4210-1657 
31 years were included in study. A questionnaire was used to obtain about general characteristics, nutrition and sleeping habits of the individuals, and Morningness-Eveningness Questionnaire (MEQ) was used to determine the chronotype. Twoday food records were completed by the participants and body weight and height measurements were taken according to the recommended procedures by researchers Meeting status the daily requirements of energy and nutrients intake of individuals were evaluated to Turkey Nutrition Guidebook.

Results: Twenty-three percent of participants had morning type ( $\mathrm{n}=186), 52.8 \%$ had intermediate type $(\mathrm{n}=426)$ and $24.2 \%$ had evening type ( $n=195$ ) chronotype. Daily water intake of morning-type individuals is significantly higher than that of intermediate and evening-type individuals $(\mathrm{p}=0.000$ ). According to the anthropometric measurements of the individuals, it was determined that the body mass index (BMI) values of morning-type individuals were higher than the evening types $(\mathrm{p}=0.014)$. In the morning-type individuals participating in the study, the proportion of those who skipped breakfast on weekdays and lunch on weekends was significantly lower than those of the evening-type $(\mathrm{p}=0.002, \mathrm{p}=0.011$, respectively). In the evening-type individuals, the percentage of daily energy from carbohydrates was higher than in the morning-type individuals $(\mathrm{p}=0.043)$. In the morning-type individuals, the percentage of daily energy from fat was higher than in the evening-type $(\mathrm{p}=0.020)$. In the morning-type subjects, the daily intake of folic acid was higher than in the evening-type subjects $(\mathrm{p}=0.018)$.

Conclusion: In this study, it was determined that although university students have different chronotypes, their food consumption is similar. The chronotype that interacts with factors such as nutrition and sleep patterns may cause changes in physiological processes. Nutritional status of university students according to their chronotype must be supported by prospective physiological studies.

Keywords: Chronotype, circadian rhythm, food consumption

\section{Gíriş}

Sirkadiyen ritim, canlı organizmalarda hücrelerin, organların, sistemlerin ve davranışların işlevlerini düzenleyen ve optimize eden 24 saatlik ritmik modellerdir $(1,2)$. Sirkadiyen ritme bağlı fizyolojik ve psikolojik değişiklikler bireysel farklılıklara göre çeşitlilik göstermektedir. Bireyler arasında görülen farklılıklarla birlikte bireylerin uyku ve diğer davranışlarının zamanlamasına ilişkin tercihleri kronotip olarak tanımlanmakta ve kronotip bireylerin akşamcıl ve sabahçıl olma eğilimlerine göre sinıflandırılmaktadır $(3,4)$. Bu sınıflamaya göre sabahçıl tiplerin akşam erken yatıp sabah erken kalktıkları, performanslarının sabah saatlerinde daha iyi olduğu, akşamcıl tiplerin gece geç saatte yattıkları, sabah güçlükle uyanabildikleri ve performanslarının öğleden sonra daha iyi olduğu belirtilmektedir (5). Bireylerin kronotiplerini etkileyen etmenler arasında genetik özellikler, yaş, etnik köken ve cinsiyet gibi çeşitli etmenler bulunmaktadır $(6,7)$.

Bireylerin kronotiplerinin beslenme düzenlerini etkilediği, özellikle sabahçıl ve akşamcıl bireylerin farklı ögün örüntülerine ve beslenme alışkanlıklarına sahip olduğu saptanmıştır (8-11). Elli iki yetişkin bireyle yürütülen bir çalışmada daha geç saatte yatan bireylerin beden kütle indekslerinin (BKİ) daha yüksek olduğu, akşam yemeklerinde ve saat 20:00'den sonra enerji alımlarının ve fast-food tüketimlerinin daha fazla, meyve ve sebze tüketimlerinin daha düşük olduğu bildirilmiştir (9). Bir başka çalışmada akşamcıl bireylerin sebze tüketimleriyle diyetle vitamin ve mineral alımlarının sabahçıllara göre daha düşük olduğu belirtilmiştir (10). Garaulet ve arkadaşları (12) tarafindan yapılan çalışmada akşamcıl bireylerin vücut ağırlıkları kayıplarının sabahçıl bireylere göre daha düşük olduğu saptanmıştır. Bu durumun obezite ile ilişkilendirilen $C L O C K$ genlerindeki tek nükleotid polimorfizmleri ile ilişkili olabileceği ve bu varyasyonların sıklığının daha geç saatte yiyen bireylerde daha fazla olabileceği öne sürülmektedir (12). 
Üniversite dönemi, sağlıksız besin seçimlerine ve olumsuz yeme davranışlarına eğilimin artabileceği kritik bir dönemdir (13,14). Bununla birlikte literatürdeki mevcut veriler ışığında akşamcıl bireylerin sabahçıl tiplere göre sağlıksız beslenmeye daha eğilimli oldukları ve buna bağlı olarak obezite, kardiyovasküler hastalıklar, tip 2 diyabet, metabolik sendrom ve gece yeme sendromu gibi hastalık risklerinin daha yüksek olduğu bilinmektedir $(9,15,16)$. Bu bağlamda bireylerin kronotiplerine göre beslenme alışkanlıklarının saptanmasının, yanlış beslenme alışkanlıklarının düzeltilmesi, hastalık risklerinin azaltılması ve sağlıklı beslenme ile öğün alışkanlıklarının kazandırılması açısından önem taşıdığı düşünülmektedir. Bu çalışmada, üniversite öğrencilerinin kronotiplerinin belirlenmesi ve kronotiplerine göre besin tüketimlerinin karşılaştırılması amaçlanmıştır.

\section{BİREYLER VE YÖNTEM}

Mayıs-Haziran 2018 tarihleri arasında gerçekleştirilen tanımlayıcı kesitsel nitelikteki bu araştırmaya Gazi Üniversitesi Sağlık Bilimleri Fakültesi’nde öğrenim görmekte olan öğrenciler dahil edilmiştir. Hekim tarafından tanısı konmuş kronik hastalığı olan, son bir ylldır doktor tarafindan reçete edilmiş düzenli ilaç, vitamin-mineral desteği ve ergojenik destek alan, gebe veya emzikli olan, günlük enerji alımı $<800 \mathrm{kkal}$ ve >3500 kkal olan bireylerle Avrupa Gida Güvenliği Otoritesi (EFSA) tarafindan yayınlanan rapora (17) göre günlük 400 mg’dan ve/veya tek seferde 200 mg'dan fazla kafein alımı olan bireylerin çalışmaya dahil edilmemesi sonucu çalışma, evreni temsil eden 807 gönüllü bireyle tamamlanmıştır. Çalışma verileri araştırmacılar tarafindan yüz yüze görüşme tekniği ile 'anket yöntemi' kullanılarak elde edilmiştir. Anket formu ile bireylerin genel bilgileri, uyku ve beslenme alışkanlıklarının yanı sıra kronotipleri ve besin tüketimleri sorgulanmıştır. Bu çalışma Gazi Üniversitesi Etik Komisyonu’nun 08.05.2018 tarihindeki 04 sayll toplantısıyla ve 77082166-604.01.02- sayll etik komisyon onayı ile gerçekleştirilmiştir. Bireylere çalışmaya katılmadan önce "Bilgilendirilmiş Gönüllü Onam Formu” imzalatılmıştır.

\section{Kronotipin Belirlenmesi}

Kronotipin belirlenmesi amacıyla "İnsan Sirkadiyen Ritminde Sabahçıl ve Akşamcıl Tipleri Belirlemede Kendi Kendini Değerlendirme Formu” kullanılmıştır $(3,5)$. Sirkadiyen tipi öznel olarak belirleyen, literatürde "Morningness-Eveningness Questionnaire (MEQ)” adıyla kullanılmakta olan anketin orijinali 1976 yılında Horne ve arkadaşları tarafından geliştirilmiştir (3). Bu ölçek, on dokuz sorudan oluşan Likert tipi bir ölçektir. Anket sonucu elde edilen puana göre bireyler 19-27 puan aralığında "sabahçıl tip", 13-18 puan aralığında "ara tip”, 6-12 puan aralığında “akşamcıl tip” olarak sinıflandırılmaktadır $(3,8)$. Ölçeğin Türkçe’ye çevirisi ve güvenilirlik çalışması 2005 yılında Pündük ve arkadaşları tarafından yapılmıştır (5).

\section{Besin Tüketiminin Saptanması}

Bireylerin besin tüketiminin saptanması amacıyla bir gün hafta içi, bir gün hafta sonuna gelecek şekilde ardışık iki günlük besin tüketim kayıtları alınmıştır. Tüketilen yiyecek ve içeceklerin ölçü ve miktarlarının belirlenmesinde "Yemek ve Besin Fotoğraf Kataloğu” kullanılarak araştırmacılar tarafından değerlendirilmiştir (18). Bireylerin tükettikleri yemeklerin içerisine girenlerin miktarları birey tarafından belirtilmediği durumda "Standart Yemek Tarifleri” kitabından yararlanılarak hesaplanmıştır $(19,20)$. Tüketilen besinlerin enerji ve besin ögesi değerleri "Beslenme Bilgi Sistemleri Paket Programı (BEBİS)” programı kullanılarak hesaplanmıştır (21). Bireylerin enerji ve besin ögesi alımları yaşa ve cinsiyete göre Türkiye Beslenme Rehberi (TÜBER,2015) önerileriyle karşılaştırılarak değerlendirilmiştir (22).

\section{Antropometrik Ölçümler}

Bireylerin antropometrik ölçümleri araştırmacılar tarafından alınmıştır. Katılımcıların vücut ağırlıkları aç karnına, hafif giysilerle ve ayakkabısız olarak 100 g hassasiyetli dijital bir tartiyla (Vestel, Bambu) ölçülmüştür. Boy uzunluğu ölçümü taşınabilir boy ölçerle standartlara uygun şekilde yapılmıştır $(23,24)$. Beden kütle indeksi [vücut ağırlığı $(\mathrm{kg}) / \mathrm{boy}^{2}\left(\mathrm{~m}^{2}\right)$ ] formülüyle hesaplanmıştır (25). 


\section{İstatistiksel Analiz}

Araştırmaya ait veriler IBM SPSS 22.0 (New York, ABD) programıyla analiz edilmiştir. Verilerin normal dağılıma uygunluğu Kolmogorov-Smirnov Testi ile değerlendirilmiştir. Normal dağılan verilerin tanımlayıcı istatistiklerinde merkezi eğilim ölçütü olarak ortalama $(\overline{\mathrm{X}})$, yayılım ölçütü olarak standart sapma (S), normal dağılmayan verilerde merkezi eğilim ölçütü olarak ortanca, yayılım ölçütü olarak çeyreklerarası aralık (25-75 persentil) kullanılmıştır. Kategorik değişkenlerin tanımlayıcı istatistiklerinde sayı (n) ve yüzde (\%) kullanılmış, bu verilerin karşılaştırılmasında çapraz tablolar ve ki-kare analizi yapılmıştır. Normal dağılan verilerin analizinde “Tek Yönlü ANOVA Testi”, post-hoc analizi için ise Tukey düzeltmesi kullanılmıştır. Normal dağılmayan verilerde ve gruplar arası karşılaştırmalarda "KruskalWallis H-Testi” uygulanmıştır. Kruskal-Wallis H-Testi'ne göre anlamlı farklılık bulunan verilerde Bonferroni düzeltmesi yapllarak "Mann-Whitney U-Testi” ikili grup karşılaştırmalarında kullanılmıştır. Bonferroni düzeltmesi sonrasında istatistiksel anlamlılık değeri $\mathrm{p}<0.017$, düzeltme yapılmayanlarda $\mathrm{p}<0.05$ olarak kabul edilmiştir (26).

\section{BULGULAR}

Araştırmaya yaşları 19-31 yıl arasında olan, 198 erkek (\%24.5) ve 609 kadın (\%75.5) olmak üzere toplam 807 üniversite öğrencisi dahil edilmiştir. Katılımclların \%23'ü sabahçıl (n= 186), \%52.8'i ara (n= 426), \%24.2'si akşamcll ( $\mathrm{n}=195)$ kronotipe sahiptir. Sabahçıl, ara ve akşamcıl bireylerin yaş ortalamaları sırasıyla $21.7 \pm 1.89,21.6 \pm 1.89,21.5 \pm 2.05$ yıldır ve üç kronotip grubunda yaşlar benzerdir $(\mathrm{p}=0.611)$ (Tablo 1). Sabahçll bireylerin \%74.2'si kadın, \%25.8'i erkek, ara tip bireylerin \%79.1'i kadın, \%20.9'u erkek iken akşamcıl bireylerin \%68.7’si kadın, \%31.3’ü erkektir.

Bireylerin uyku alışkanlıkları incelendiğinde üç kronotip grubu arasında hafta içi ve hafta sonu uyku süreleri açısından fark olmadığı saptanmıştır ( $p>0.05$ ). Sabahçl bireylerin hafta içi ve hafta sonu ara ve akşamcıl bireylerden daha erken saatte yatıp daha erken saatte kalktıkları, akşamcıl bireylerin ise en geç yatış-kalkış saatine sahip grup olduğu belirlenmiştir. Sabahçll bireylerin BKİ değerlerinin akşamcıl tiplere göre daha yüksek olduğu saptanmıştır $(p=0.014)$ (Tablo 1).

Tablo 1. Kronotipe göre bireylerin genel özellikleri ve antropometrik ölçümleri

\begin{tabular}{|c|c|c|c|c|}
\hline & $\begin{array}{c}\text { Sabahçıl tip } \\
(n=186)\end{array}$ & $\begin{array}{l}\text { Ara tip } \\
(n=426)\end{array}$ & $\begin{array}{c}\text { Akşamcıl tip } \\
(n=195)\end{array}$ & $\mathbf{p}$ \\
\hline & $\overline{\mathrm{X}} \pm \mathrm{S}$ & $\overline{\mathrm{X}} \pm \mathbf{S}$ & $\overline{\mathrm{X}} \pm \mathbf{S}$ & \\
\hline Yaş (yıl) & $21.7 \pm 1.89$ & $21.6 \pm 1.89$ & $21.5 \pm 2.05$ & 0.700 \\
\hline \multicolumn{5}{|l|}{ Uyku süresi (saat) } \\
\hline Hafta içi & $7.2 \pm 1.03$ & $7.3 \pm 1.15$ & $7.1 \pm 1.27$ & 0.192 \\
\hline Hafta sonu & $8.4 \pm 1.14$ & $8.6 \pm 1.20$ & $8.5 \pm 1.43$ & 0.145 \\
\hline \multicolumn{5}{|l|}{ Yatış saati } \\
\hline Hafta içi & $00: 05 \pm 0: 52^{a, b}$ & $00: 21 \pm 0: 51^{\mathrm{a}, \mathrm{c}}$ & $01: 04 \pm 1: 10^{\mathrm{b}, \mathrm{c}}$ & $0.000^{\mathrm{a}, \mathrm{b}, \mathrm{c}}$ \\
\hline Hafta sonu & $00: 43 \pm 0: 58^{\mathrm{a}, \mathrm{b}}$ & $01: 05 \pm 1: 11^{\mathrm{a}, \mathrm{c}}$ & $01: 56 \pm 1: 15^{\mathrm{b}, \mathrm{c}}$ & $0.000^{a, b, c}$ \\
\hline \multicolumn{5}{|l|}{ Kalkış saati } \\
\hline Hafta içi & $07: 19 \pm 0: 55^{\mathrm{a}, \mathrm{b}}$ & $07: 40 \pm 1: 02^{\mathrm{b}, \mathrm{c}}$ & $08: 10 \pm 1: 24^{\mathrm{a}, \mathrm{c}}$ & $0.000^{\mathrm{a}, \mathrm{b}, \mathrm{c}}$ \\
\hline Hafta sonu & $09: 12 \pm 1: 22^{a, b}$ & $09: 47 \pm 1: 14^{\mathrm{b}, \mathrm{c}}$ & $10: 25 \pm 1: 22^{\mathrm{a}, \mathrm{c}}$ & $0.000^{\mathrm{a}, \mathrm{b}, \mathrm{c}}$ \\
\hline Vücut ağırlığı (kg) & $63.7 \pm 12.55$ & $61.2 \pm 11.91$ & $61.5 \pm 11.51$ & 0.054 \\
\hline Boy uzunluğu (cm) & $167.9 \pm 8.70$ & $166.6 \pm 8.12^{\mathrm{a}}$ & $168.7 \pm 8.86^{\mathrm{a}}$ & $0.012^{\mathrm{a}}$ \\
\hline BKİ $\left(\mathrm{kg} / \mathbf{m}^{2}\right)^{*}$ & $21.9(20.1-24.5)^{a, b}$ & $21.4(19.7-23.6)^{\mathrm{b}}$ & $21.2(19.3-24.5)^{\mathrm{a}}$ & $0.021^{a, b}$ \\
\hline
\end{tabular}


Araştırmaya katılan sabahçıl bireylerde hafta içi sabah öğününü, hafta sonu ise öğle öğününü atlayanların oranı akşamcıl bireylere göre daha azdır (sırasıyla $\mathrm{p}=0.002, \mathrm{p}=0.011$ ). Hafta içi ve hafta sonu öğle öğününü atlayanların oranı ise akşamcıl bireylerde ara tipe göre daha azdır (sirasıyla $\mathrm{p}=0.005$, $\mathrm{p}=0.011$ ) (Tablo 2).

Sabahçll bireylerin hafta içi ve hafta sonu ana öğünlerini akşamcıl bireylere göre daha erken saatlerde yaptıkları saptanmıştır $(\mathrm{p}<0.05)$ (Tablo 3).

Akşamcıl bireylerin ekmek tüketimleri sabahçıl ve ara tip bireylerden daha fazladır ( $\mathrm{p}=0.033)$. Günlük kurubaklagil tüketimi ara tip bireylerde akşamcıl bireylere göre daha yüksektir ( $p=0.046)$. Günlük su tüketimi en fazla olan grup sabahçıl tip iken en düşük olan akşamcıl tiptir (sırasıyla p=0.000, p=0.000) (Tablo 4).

Tablo 2. Kronotipe göre bireylerin hafta içi ve hafta sonu öğün tüketim durumları

\begin{tabular}{|c|c|c|c|c|c|c|c|}
\hline \multirow[b]{2}{*}{ Öğünler } & \multicolumn{2}{|c|}{ Sabahçıl tip $(n=186)$} & \multicolumn{2}{|c|}{ Ara tip $(n=426)$} & \multicolumn{2}{|c|}{ Akşamcıl tip $(n=195)$} & \multirow[b]{2}{*}{$\mathbf{p}$} \\
\hline & $\begin{array}{l}\text { Atlar } \\
\text { n (\%) }\end{array}$ & $\begin{array}{c}\text { Atlamaz } \\
\text { n (\%) }\end{array}$ & $\begin{array}{l}\text { Atlar } \\
\text { n (\%) }\end{array}$ & $\begin{array}{c}\text { Atlamaz } \\
\text { n (\%) }\end{array}$ & $\begin{array}{l}\text { Atlar } \\
\text { n (\%) }\end{array}$ & $\begin{array}{c}\text { Atlamaz } \\
\text { n (\%) }\end{array}$ & \\
\hline Sabah & $14(7.5)^{\mathrm{b}}$ & $172(92.5)$ & $48(11.3)^{\mathrm{a}}$ & $378(88.7)$ & $37(19.0)^{\mathrm{a}, \mathrm{b}}$ & $158(81.0)$ & $0.002^{a, b}$ \\
\hline Öğle & $34(18.3)$ & $152(81.7)$ & $65(15.3)^{\mathrm{a}}$ & $361(84.7)$ & $51(26.2)^{\mathrm{a}}$ & $144(73.8)$ & $0.005^{a}$ \\
\hline \multicolumn{8}{|c|}{ Hafta sonu } \\
\hline Sabah & $14(7.5)$ & $172(92.5)$ & $36(8.5)$ & $390(91.5)$ & $24(12.3)$ & $171(87.7)$ & 0.205 \\
\hline Öğle & $45(24.2)^{\mathrm{b}}$ & $141(75.8)$ & $111(26.1)^{\mathrm{a}}$ & 315 (73.9) & $71(36.4)^{\mathrm{a}, \mathrm{b}}$ & $124(63.6)$ & $0.011^{a, b}$ \\
\hline Akşam & $3(1.6)$ & $183(98.4)$ & $3(0.7)$ & $423(99.3)$ & $1(0.5)$ & $194(99.5)$ & 0.445 \\
\hline
\end{tabular}

$\overline{a-b-c \cdot A y n ı ~ s a t ı r d a ~ a y n ı ~ h a r f ~ u ̈ s t u ̈ ~ i l e ~ g o ̈ s t e r i l e n ~ d e g ̆ e r l e r ~ a r a s ı n d a k i ~ f a r k ~ i s t a t i s t i k s e l ~ o l a r a k ~ a n l a m l ı d ı r(~} p<0.05)$

Tablo 3. Kronotipe göre bireylerin hafta içi ve hafta sonu öğün tüketim zamanları

\begin{tabular}{|c|c|c|c|c|}
\hline Öğünler & $\begin{array}{c}\text { Sabahçıl tip }(n=186) \\
\bar{X}_{ \pm S}\end{array}$ & $\begin{array}{l}\text { Ara tip }(n=426) \\
\bar{X}_{ \pm S}\end{array}$ & $\begin{array}{c}\text { Akşamcıl tip }(n=195) \\
\bar{X}_{ \pm S}\end{array}$ & $\mathbf{p}$ \\
\hline \multicolumn{5}{|l|}{ Hafta içi } \\
\hline Sabah & $8: 08^{\mathrm{b}} \pm 1: 02$ & $8: 19^{a} \pm 1: 04$ & $8: 48^{\mathrm{a}, \mathrm{b}} \pm 1: 28$ & $0.000^{a, b}$ \\
\hline Öğle & $12: 30^{\mathrm{a}} \pm 0: 40$ & $12: 34 \pm 0: 44$ & $12: 44^{\mathrm{a}} \pm 0: 57$ & $0.031^{a}$ \\
\hline Akşam & $18: 10 \mathrm{a}, \mathrm{b} \pm 0: 53$ & $18: 26 b \pm 1: 02$ & $18: 34^{\mathrm{a}} \pm 1: 10$ & $0.001^{\mathrm{a}, \mathrm{b}}$ \\
\hline \multicolumn{5}{|c|}{ Hafta sonu } \\
\hline Sabah & $9: 59^{\mathrm{a}, \mathrm{b}} \pm 1: 10$ & $10: 22^{b, c} \pm 1: 07$ & $10: 47^{\mathrm{a}, \mathrm{c}} \pm 1: 15$ & $0.000^{\mathrm{a}, \mathrm{b}, \mathrm{c}}$ \\
\hline Öğle & $13: 43^{\mathrm{a}} \pm 0: 55$ & $13: 53 \pm 1: 03$ & $14: 07^{\mathrm{a}} \pm 1: 12$ & $0.013^{a}$ \\
\hline Akşam & $18: 35^{\mathrm{a}, \mathrm{b}} \pm 1: 01$ & $18: 50^{\mathrm{b}, \mathrm{c}} \pm 1: 09$ & $19: 09^{\mathrm{a}, \mathrm{c}} \pm 1: 14$ & $0.000^{\mathrm{a}, \mathrm{b}, \mathrm{c}}$ \\
\hline
\end{tabular}

$\overline{a-b-c-c}$ Aynı satırda aynı harf üstü ile gösterilen değerler arasındaki fark istatistiksel olarak anlamlıdır( $p<0.05)$

Ara tip bireylerin günlük önerilen yeterli enerji alım miktarlarını karşılama yüzdesi akşamcıl ( $p=0.018)$ tipten daha fazla iken sabahçll tiple benzerdir ( $p>0.05$ ). Akşamcıl bireylerin günlük enerjinin karbonhidrattan gelen yüzdesi ve önerilen miktarı karşılama düzeyleri sabahçıl bireylerden daha fazladır ( $\mathrm{p}=0.043)$. Sabahçıl bireylerin günlük enerjinin yağdan gelen yüzdesi ve karşlama düzeyleri akşamcll bireylere göre daha fazladır ( $p=0.020$ ) (Tablo 5). Sabahçıl bireylerin günlük folik asit alımları ve önerilen düzeyleri karşılama yüzdeleri akşamcıl bireylere göre daha fazladır $(\mathrm{p}=0.018)$ (Tablo 6). 
Tablo 4. Kronotipe göre bireylerin günlük besin grupları ve su tüketim miktarları

\begin{tabular}{lcccc}
\hline \multirow{2}{*}{ Besinler } & Sabahçll tip (n=186) & Ara tip (n=426) & Akşamcll tip (n=195) & p \\
\cline { 2 - 4 } & Ortanca (25-75 per) & Ortanca (25-75 per) & Ortanca (25-75 per) & \\
\hline Süt-yoğurt & $116.3(55-220)$ & $115.0(58-200)$ & $125.0(62.5-212.5)$ & 0.731 \\
Peynir & $30.0(15-45)$ & $30.0(15-45)$ & $30.0(15-45)$ & 0.810 \\
Yumurta & $26.0(7.5-50.5)$ & $26.0(7.5-50)$ & $25.0(5-50)$ & 0.746 \\
Et & $78.8(45-125)$ & $80.0(45-132)$ & $90.0(51-145)$ & 0.094 \\
Kuru baklagiller & $12.5(0-25)$ & $10.0(0-25)^{\mathrm{a}}$ & $10.0(0-25)^{\mathrm{a}}$ & $\mathbf{0 . 0 4 6}^{\mathrm{a}}$ \\
Yağlı tohumlar & $0.0(0-5)$ & $0.0(0-10)$ & $0.0(0-5)$ & 0.050 \\
Sebze & $226.5(142.5-310)$ & $211.3(143.5-289.5)$ & $212.5(130-303.5)$ & 0.432 \\
Meyve & $115.0(25-205.5)$ & $107.3(22.5-190)$ & $89.0(13-200.5)$ & 0.315 \\
Ekmek & $87.5(50-125)^{\mathrm{a}}$ & $100.0(60-140)$ & $100.0(70-145)^{\mathrm{a}}$ & $\mathbf{0 . 0 3 3 ^ { \mathrm { a } }}$ \\
Diğer tahıllar & $98.8(67.5-151.5)$ & $107.0(75.5-147.5)$ & $100.0(60.5-140)$ & 0.119 \\
Toplam yağ & $35.8(23.5-49)$ & $35(23.5-47)$ & $32.5(22.5-43.5)$ & 0.078 \\
Şeker ve şekerli ürünler & $10.0(0-24)$ & $10.3(0-26.5)$ & $11.0(0-25)$ & 0.673 \\
Su (mL) & $1600(1000-2000)^{\mathrm{a}, \mathrm{b}}$ & $1200(1000-1800)^{\mathrm{b}, \mathrm{c}}$ & $1000(800-1600)^{\mathrm{a}, \mathrm{c}}$ & $\mathbf{0 . 0 0 0}^{\mathrm{a}, \mathrm{b}, \mathbf{c}}$ \\
\hline
\end{tabular}

$\overline{a-b-c}$ Aynı satırda aynı harf üstü ile gösterilen değerler arasındaki fark istatistiksel olarak anlamlıdır( $p<0.05)$, per: persentil

\section{TARTIŞMA}

Sirkadiyen saat, gen ekspresyonu, uyku, fiziksel ve bilişsel performans gibi pek çok fizyolojik sürece etki etmektedir (27). Sirkadiyen ritimle ilişkili olarak kronotip sinıflaması incelendiğinde sabahçıl tiplerin akşam erken yatıp sabah erken kalktıkları, akşamcıl tiplerin ise gece geç saatte yattıkları, sabah güçlükle uyanabildikleri belirtilmektedir (5,28). Mevcut çalışmada sabahçıl bireylerin hafta içi ve hafta sonu ara tip ve akşamcll bireylerden daha erken saatte yatıp daha erken saatte kalktıkları, akşamcıl bireylerin ise en geç yatış ve kalkış saatine sahip grup olduğu belirlenmiştir.

Son dönemde enerji regülasyonu davranışsal, fizyolojik ve moleküler düzeyde sirkadiyen saate bağlanarak, besin alımının zamanlamasının obezitede önemli bir rol oynayabileceği vurgulanmaktadır (29). Öğle yemeğini daha geç saatte yiyen bireylerin vücut ağırlığı kaybı başarısının daha düşük olduğu saptanmıştır (12). Bu farklılığın uyku süresindeki farklılıklar, sirkadiyen ritmin bozulmasına bağlı olarak leptin ve ghrelin gibi iştahtan sorumlu hormonların dolaşımdaki düzeylerinin değişimine bağlı enerji alımı/harcamasındaki değişiklikler ve geç saatte besin tüketen bireylerde CLOCK genindeki varyasyonların yanı sira bireylerin kronotiplerine bağlı olarak sirkadiyen ritimdeki faz gecikmesinden kaynaklanabileceği belirtilmektedir Literatürdeki çeşitli çalışmalar akşamcıl bireylerin BKİ değerlerinin daha yüksek olduğunu ve buna bağlı olarak obezite gelişme riskinin daha yüksek olduğunu öne sürmektedir (30,31). Bu çalışmada diğer çalışmalardan farklı olarak sabahçıl bireylerin BKİ değerlerinin akşamcıl tipe göre daha yüksek olduğu saptanmıştır. Bu durum araştırmaya katılan sabahçıl öğrencilerin günlük enerjinin yağdan gelen yüzdesinin akşamcıl bireylere göre daha fazla olması ile açıklanabilir. Buna ek olarak çalışmanın okul döneminde yapılmış olmasına bağlı olarak alınan besin tüketim kayıtlarının normal tüketimleri yansıtmamış olabileceği de düşünülmektedir. Bununla birlikte mevcut çalışmanın limitasyonlarından biri olarak fiziksel aktivite düzeyleri belirlenememiştir. Tüm kronotip gruplarında benzer enerji alımlarına rağmen fiziksel aktivite düzeyindeki farklılıklar BKİyi etkileyebilir. 


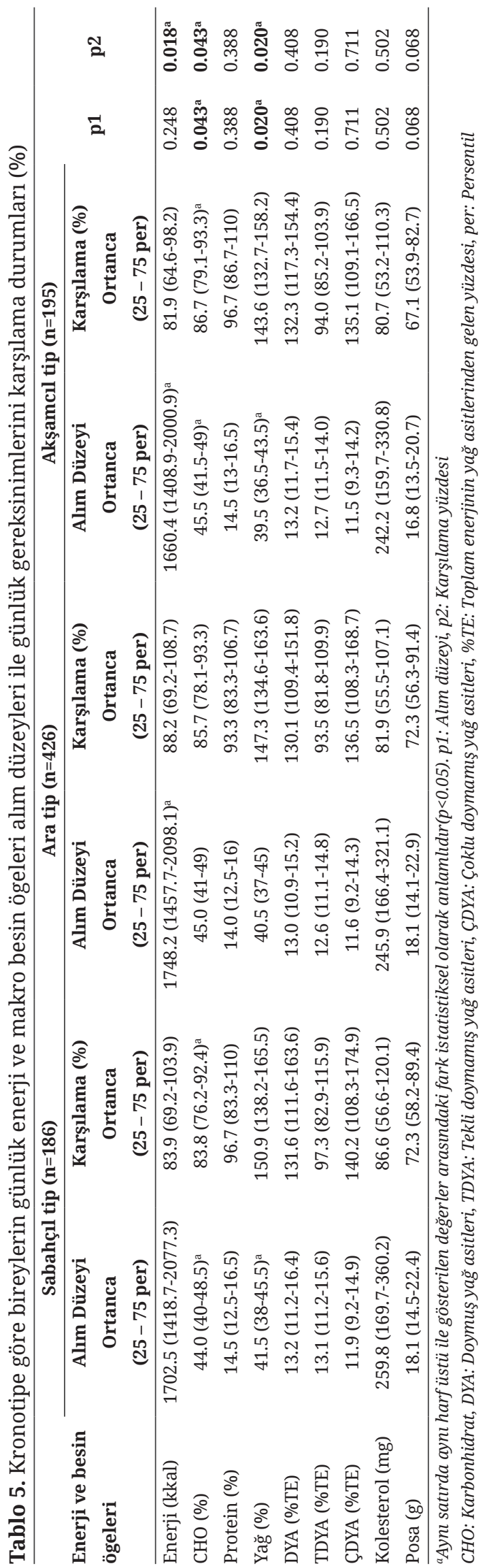




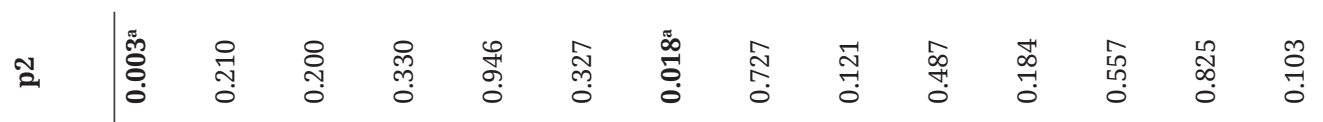

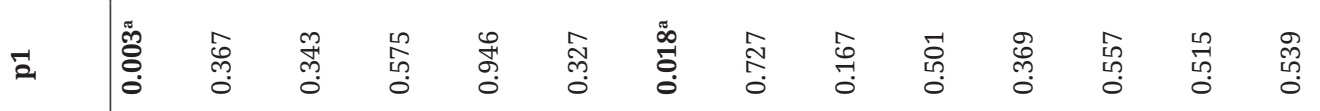

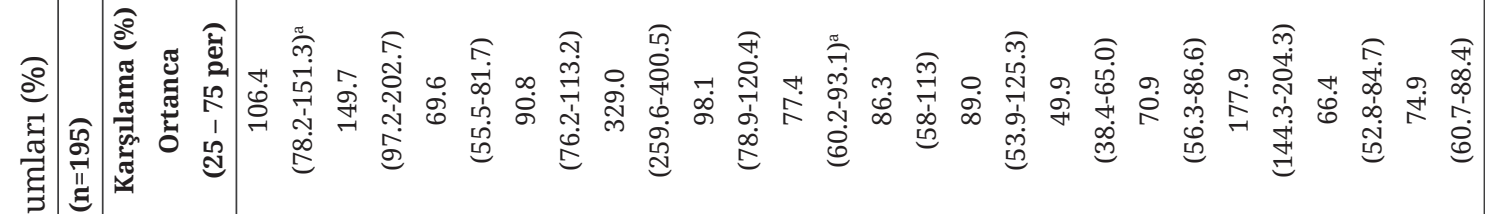

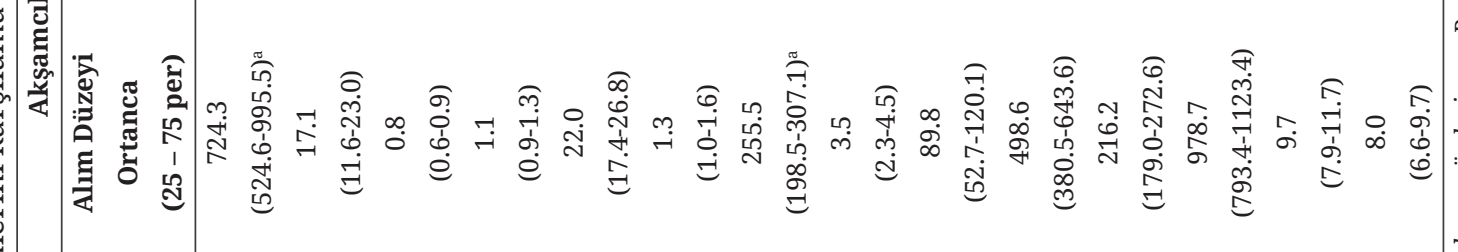

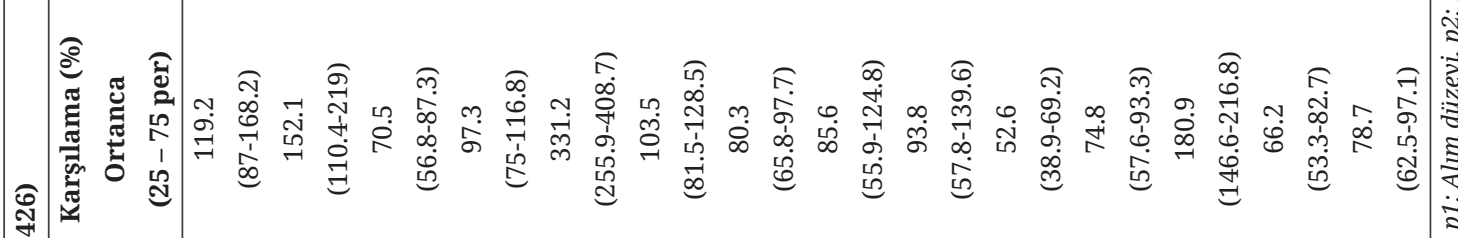

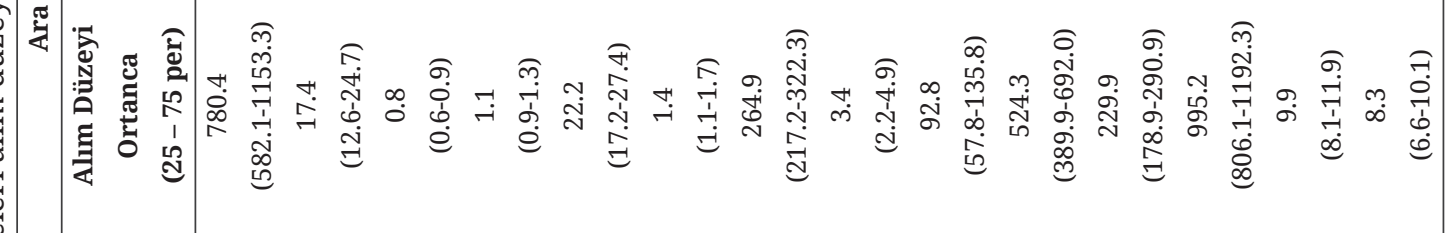


Sirkadiyen ritme bağlı olarak bireylerin öğün zamanları ve sayıları farklılık gösterebilmektedir (32). Yapılan bir çalışmada akşamcıl bireylerin öğünlerini daha geç saatte yaptıkları, daha sık öğün atladıkları belirtilmiştir (10). Lucassen ve arkadaşları (4) tarafindan yürütülen çalışmada ise akşamcıl bireylerin öğün sayılarının daha az olduğu ve öğünlerini daha geç saatte tükettikleri ifade edilmiştir. Mevcut çalışmada sabahçıl bireylerde hafta içi sabah öğününü, hafta sonu ise öğle öğününü atlayanların oranı akşamcıl bireylere göre daha azdır. Hafta içi ve hafta sonu öğle öğününü atlayanların oranı ise akşamcıl bireylerde ara tipe göre daha azdır. Ayrıca sabahçıl bireylerin hafta içi ve hafta sonu ana öğünleri akşamcıl bireylere göre daha erken saatlerde yaptıkları saptanmıştır. Sabahçıl bireylerdeki düzenli kahvaltı alışkanlığının iyi/düzenli bir uyku ile ilişkili olduğu düşünülmektedir. Bununla birlikte akşamcıl bireylerin geç kalkması ve evden çıkmadan önce kahvaltı yapmaya zamanları olmamasına ek olarak sosyal jetlagın kahvaltı öğününü atlamalarında ve öğün saatlerinin kaymasında etkili olabileceği söylenebilir.

$\mathrm{Su}$ tüketimi hücresel homeostaz ve yaşamsal işlevlerin devamlılığı için elzemdir. Dehidrasyon olarak adlandırılan, vücutta ideal hidrasyon durumunun sağlanamaması sonucu fiziksel ve bilişsel işlevlerde bozulmalar meydana gelmektedir (33). Mevcut çalışmada ara ve akşamcıl bireylerin TÜBER'de önerilen günlük su tüketim miktarlarını karşılayamadıkları saptanmıştır. Bununla birlikte sabahçıl bireylerin günlük su tüketimlerinin daha fazla olduğu, günlük en az su tüketiminin ise akşamcll bireylere ait olduğu belirlenmiştir. Bireylerin besin tüketim kayıtları incelendiğinde akşamcıl bireylerin kafein içeren içecekleri daha fazla tükettikleri belirlenmiştir. Bu nedenle su tüketimlerinin sabahçıl bireylere göre daha az olabileceği düşünülmektedir.

Sato-Mito ve arkadaşları (10) akşamcıl bireylerin günlük kalsiyum, çinko ve riboflavin alımlarının daha düşük olduğunu belirlemişlerdir. Kanerva ve arkadaşları (34) tarafından yapılan, yaşları 25-74 yıl arasında değişen 4493 kişinin dahil edildiği çalışmada ise bireylerin akşamcılığa olan eğiliminin artmasıyla birlikte folik asit ve posa alımının azaldığı saptanmıștır. Bu çalışmada sabahçıl bireylerin günlük kurubaklagil, akşamcll bireylerin ise ekmek grubundan tüketim miktarları daha fazla iken kronotipler arasında diğer besin gruplarının tüketimi açısından farklılık bulunmamaktadır. Sabahçll bireylerde enerjinin yağdan gelen yüzdesi akşamcıl bireylere göre, akşamcll bireylerde enerjinin karbonhidrattan gelen yüzdesi sabahçlllara göre daha yüksektir. Bununla birlikte sabahçıl bireylerin günlük folik asit alımları akşamcll bireylere göre daha fazlayken diğer mikro besin ögeleri ile posa ve kolesterol alımları benzerdir. $\mathrm{Bu}$ çalışmada sabahçıl ve akşamcıl bireylerin besin tüketimlerinin benzerliği sabahçıl bireylerin öğün atlamamalarına rağmen dönemsel olarak sağlıksız besin seçimlerinden kaynaklanmış olabilir.

Literatürde yapılan çeşitli çalışmalar kronotip ile beslenme arasındaki ilişkiyi ortaya koymaktadır. Ülkemizde üniversite öğrencilerinde kronotipin belirlenmesi ve kronotiplerine göre besin tüketimlerinin karşılaştırılmasına ilişkin çalışmalar yok denecek kadar azdır. Bu çalışmada farklı kronotipe sahip üniversite öğrencilerinin besin tüketimleri, enerji, makro ve mikro besin ögeleri alımları arasında belirgin bir farklılık saptanamamıştır. Mevcut çalışmadaki sınırlılıklar dikkate alınarak kronotip ve beslenme arasındaki ilişkinin saptanması ve mekanizmaların daha net ortaya konabilmesi için prospektif fizyolojik çalışmaların yapılması yararlı olacaktır.

Çıkar çatışması - Conflict of interest: Yazarlar çıkar çatışması olmadığını beyan ederler. - The authors declare that they have no conflict of interest.

\section{KAYNAKLAR}

1. Voigt RM, Forsyth CB, Green SJ, Engen PA, Keshavarzian A. Circadian rhythm and the gut microbiome. In International Review of Neurobiology 131. 1st ed. Elsevier Inc; 2016. p. 193-205.

2. Mohawk JA, Green CB, Takahashi JS. Central and peripheral circadian clocks in mammals. Annu Rev Neurosci 2012;35:445-462. 
3. Horne JA, Östberg O. A self-assessment questionnaire to determine morningness-eveningness in human circadian rhythms. Int J Chronobiol 1976;4(2):97-110.

4. Lucassen EA, Zhao X, Rother K, Mattingly MS, Courville $\mathrm{AB}$, de Jonge L, et al. Evening chronotype is associated with changes in eating behavior, more sleep apnea, and increased stress hormones in short sleeping obese individuals. PLoS One 2013;8(3):e56519.

5. Pündük Z, Gür H, Ercan İ. Sabahçll-akşamcıl anketi Türkçe uyarlamasında güvenilirlik çalışması. Turk Psikiyatri Derg 2005;16(1):40-45.

6. Adan A, Archer SN, Hidalgo MP, Di Milia L, Natale V, Randler C. Circadian typology: a comprehensive review. Chronobiol Int 2012;29(9):1153-1175.

7. Kalmbach DA, Schneider LD, Cheung J, Bertrand SJ, Kariharan T, Pack A, et al. Genetic basis of chronotype in humans: Insights from three landmark GWAS. Sleep 2017;1;40(2).

8. Maukonen M, Kanerva N, Partonen T, Kronholm E, Tapanainen H, Kontto J, et al. Chronotype differences in timing of energy and macronutrient intakes: A population-based study in adults. Obesity 2017;25(3):608615.

9. Baron KG, Reid KJ, Kern AS, Zee PC. Role of sleep timing in caloric intake and BMI. Obesity 2011;19(7):1374-1381.

10. Sato-Mito N, Shibata S, Sasaki S, Sato K. Dietary intake is associated with human chronotype as assessed by both morningness-eveningness score and preferred midpoint of sleep in young Japanese women. Int J Food Sci Nutr 2011;62(5):525-532.

11. Fleig D, Randler C. Association between chronotype and diet in adolescents based on food logs. Eat Behav 2009;10(2):115-118.

12. Garaulet M, Gómez-Abellán P, Alburquerque-Béjar JJ, Lee YC, Ordovás JM, Scheer FA. Timing of food intake predicts weight loss effectiveness. Int J Obes (Lond) 2013;37(4):604-611.

13. Deliens T, Clarys P, Bourdeaudhuij ID, Deforche B. Determinants of eating behaviour in university students: a qualitative study using focus group discussions. BMC Public Health 2014;14(1):53.

14. Bernardo GL, Jomori MM, Fernandes AC, Proença RPDC. Food intake of university students. Rev Nutr 2017;30(6):847-865.

15. Reutrakul S, Hood MM, Crowley SJ, Morgan MK, Teodori $\mathrm{M}$, Knutson KL, et al. Chronotype is independently associated with glycemic control in type 2 diabetes. Diabetes Care 2013;36(9):2523-2529.

16. Garaulet M, Ordovas JM, Madrid JA. The chronobiology, etiology and pathophysiology of obesity. Int J Obes (Lond) 2010;34(12):1667-1683.
17. European Food Safety Authority (EFSA) NDA Panel (EFSA Panel on Dietetic Products, Nutrition and Allergies). Scientific opinion on the safety of caffeine. EFSA Journal 2015;13(5):4102.

18. Rakıcıoğlu N, Acar-Tek N, Ayaz A, Pekcan G. Yemek ve besin ve fotoğraf kataloğu:ölçü ve miktarlar. 4. Baskı. Ata Ofset Matbaacılık, Ankara, 2012.

19. Baysal A, Kutluay Merdol T, Ciğerim N, Sacır H, Başoğlu S. Türk Mutfağından Örnekler. 4. Baskı. Hatiboğlu Yayınevi, Ankara, 2000.

20. Kutluay Merdol T. Toplu Beslenme Yapllan Kurumlar İçin Standart Yemek Tarifeleri. 3. baskı. Hatipoğlu Yayınevi, Ankara, 1994.

21. BeBİs (Beslenme Bilgi Sistemi) bilgisayar yazılım programı versiyon 7.2. 2011: Stuttgart, Germany.

22. Türkiye Beslenme Rehberi TÜBER 2015, T.C. Sağllk Bakanlı̆̆ı Yayın No:1031, Ankara, 2016.

23. Pekcan, G. Beslenme durumunun saptanması. (Eds. Baysal A, Aksoy M, Besler T, Bozkurt N, Keçecioğlu S, Kutluay Merdol T ve arkadaşları) Diyet El Kitabi. 11. Baskı. Hatipoğlu Basım ve Yayım San. Tic. Ltd. Şti. Ankara, 2008, s. 67-141.

24. Gibson R. Principles of Nutritional Assessment. 2nd Ed. USA: Oxford University Press: 2005. p. 245-50.

25. World Health Organization (WHO). Obesity: Preventing And Managing The Global Epidemic, 2000. Available at: http://www.who.int/nutrition/publications/obesity/ WHO_TRS_894/en/ Accessed May 01, 2018.

26. Hayran M, Hayran M. Saglık Araştırmaları İçin Temel İstatistik. 1. Baskı. Art Ofset Matbaacılık Yayıncılık Organizasyon Ltd. Şti. Ankara, 2011.

27. Roenneberg TA, Wirz-Justice A, Merrow M. Life between clocks: daily temporal patterns of human chronotypes. J Biol Rhythms 2003;18(1):80-90.

28. Roepke SE, Duffy JF. Differential impact of chronotype on weekday and weekend sleep timing and duration. Nat Sci Sleep 2010;2:213-220.

29. Garaulet M, Gómez-Abellán P. Timing of food intake and obesity: a novel association. Physiol Behav 2014;134:4450.

30. Ruiz-Lozano T, Vidal J, de Hollanda A, Canteras M, Garaulet M, Izquierdo-Pulido M. Evening chronotype associates with obesity in severely obese subjects: interaction with CLOCK 3111T/C. Int J Obes (Lond) 2016;40(10):1550.

31. Culnan E, Kloss JD, Grandner M. A prospective study of weight gain associated with chronotype among college freshmen. Chronobiol Int 2013;30(5):682-690.

32. Cagampang FR, Bruce KD. The role of the circadian clock system in nutrition and metabolism. Br J Nutr 2012;108(3):381-392. 
33. Popkin BM, D’Anci KE, Rosenberg IH. Water, hydration, and health. Nutr Rev 2010;68(8):439-458.

34. Kanerva N, Kronholm E, Partonen T, Ovaskainen ML,
Kaartinen NE, Konttinen $\mathrm{H}$, et al. Tendency toward eveningness is associated with unhealthy dietary habits. Chronobiol Int 2012;29(7):920-927. 